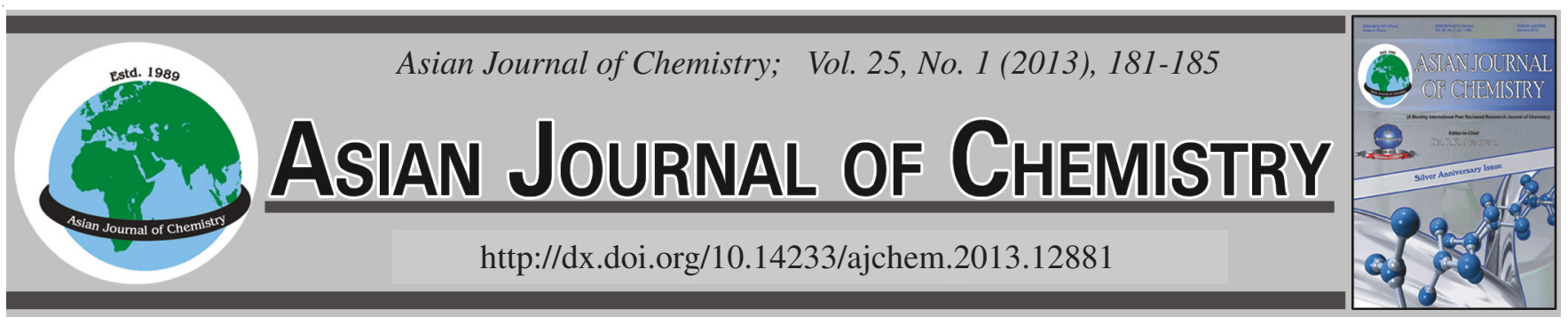

\title{
Study on Ammonia-Based Selective Catalytic Reduction and the Dosing Control Strategy Based on a V-W/Ti Catalyst
}

\author{
Shuzhan Bai ${ }^{1,2}$, Jianzhong TaO ${ }^{2}$, Qiang Sun ${ }^{1}$, Dehui Tong ${ }^{2}$ and Guoxiang Li ${ }^{1, *}$
}

${ }^{1}$ School of Energy and Power Engineering, Shandong University, Jinan 250061, P.R. China

${ }^{2} \mathrm{R} \&$ D Center, Weichai Power Co. Ltd., Weifang 261041, P.R. China

*Corresponding author: Fax: +86 531 88392701; Tel: +86 531 88395623; E-mail: liguox_baishzh@163.com

(Received: 18 October 2011;

Accepted: 16 July 2012)

AJC-11844

\begin{abstract}
In present work, $\mathrm{V}_{2} \mathrm{O}_{5}-\mathrm{WO}_{3} / \mathrm{TiO}_{2}$ catalyst was prepared and a dosing strategy for the transient control of an exhaust after-treatment system using the ammonia-based selective catalytic reduction was developed on an $11.6 \mathrm{~L}$ heavy-duty diesel engine. NOx reduction characteristics of prepared catalyst were measured using simulating gas test equipment, its conversion efficiency was higher $10 \%$ than that of the commercial catalyst from 240 and $410{ }^{\circ} \mathrm{C}$ and it was lower $10 \%$ than that of the commercial catalyst from 410 to $500{ }^{\circ} \mathrm{C}$. The dosing strategy with and without dynamic correction have been tested in the European steady state cycle and European transient cycle, results indicate that with correction could meet emission standard and decrease urea consumption obviously and it can decrease $\mathrm{NH}_{3}$ slip effectively at transient work conditions.
\end{abstract}

Key Words: Selective catalytic reduction, Urea dosing strategy, Nitrogen oxides.

\section{INTRODUCTION}

With the aggravation of environmental pollution and the concern to human health, as well as stringent exhaust emission standards, it is the best method to develop the advanced technology about diesel engines and exhaust after-treatments for reducing the pollutants from vehicles. Promising techniques include delayed fuel injection timing, exhaust gas recirculation, high pressure common rail technology and catalytic reduction of NOx. The selective catalytic reduction (SCR) method using zeolite and alumina-based catalyst has been considered as the most promising technique for the removal of nitrogen oxides from the exhaust of heavy-duty diesel vehicles ${ }^{1,2}$. The use of an selective catalytic reduction system can improve the economy of the engine together with the reduction of NOx emissions ${ }^{3}$. Hums et al. ${ }^{4}$ have reported that a compact ureaselective catalytic reduction system reduced more than $70 \%$ NOx when evaluated on the European transient cycle (ETC) and European steady state cycle (ESC). Parvulescu et al. ${ }^{5}$ reviewed different aspects of the selective catalytic reduction technology.

As far as its development is concerned, the selective catalytic reduction system was operated initially in heavy duty engines in early 1992 by a consortium of four initial partners belonging to European union ${ }^{6}$. Using urea solution as reductant, Koebel et al. ${ }^{1}$ studied the selective catalytic reduction system and reported that it was a good technique for stationary applications. In spite of this, some limitations of urea-selective catalytic reduction have also been reported, for example, if the injected urea solution fails to be decomposed completely under $200{ }^{\circ} \mathrm{C}$, ammonium nitrate $\left(\mathrm{NH}_{4} \mathrm{NO}_{3}\right)$, cyanuric acid $\left[(\mathrm{HNCO})_{3}\right]$, etc., are produced as byproducts ${ }^{7}$, Kowatari et al. ${ }^{8}$ designed a new dosing device for enhancing low temperature performance of urea-selective catalytic reduction in order to solve this problem. Lei et al. ${ }^{9}$ studied unregulated emissions form diesel engine equipped with urea-selective catalytic reduction, but there were still some unregulated by products emission ${ }^{9}$. However, the $\mathrm{NH}_{3}$ slip and the control strategy for transient state and should be paid more attention when the vehicle running on the road.

The present study focused on the investigation of NOx reduction efficiency using $\mathrm{NH}_{3}$ as the reducing agent based on nanometer class V-W/Ti catalyst and usage on a $12 \mathrm{~L}$ diesel engine. The dynamic correction for transient state and $\mathrm{NH}_{3}$ slip with user-selective catalytic reduction were also discussed in this paper.

\section{EXPERIMENTAL}

\section{Catalyst preparation and performance}

Catalyst preparation: Many research efforts have been made to investigate the appropriate catalytic systems and to study the mechanistic backgrounds of the processes on the catalyst surface. Vanadia-based catalyst were considered to 
be more effective with $\mathrm{WO}_{3}$ support ${ }^{10}$ and zeolites were developed as second generation catalysts ${ }^{11}$. $\mathrm{V}_{2} \mathrm{O}_{5}-\mathrm{WO}_{3} / \mathrm{TiO}_{2}$ catalyst was prepared and used for this study. The procedures followed as follows: Firstly, proper mixing solution of $\mathrm{NH}_{4} \mathrm{VO}_{3}$ and $\mathrm{H}_{2} \mathrm{C}_{2} \mathrm{O}_{4}$ was solved in proper de-ionized water; secondly, some aluminosilicate was added in as plastering agent and the solution was decanted to a beater subsequently, the nano-phase $\mathrm{WO}_{3}$ powder was put in when the beater working, the $\mathrm{pH}$ value and dimension of $\mathrm{D}_{90}$ were measured after $2 \mathrm{~h}$, if they were meet the challenge, then go to next step; thirdly, the cordierite ceramic honeycomb carrier was dipping in the solution using immersion method, it was taken out subsequently, the moisture content was evaporated equably by blow out and oven-dried at $110^{\circ} \mathrm{C}$ in a bake oven. It was then subjected to natural cooling to room temperature and weighing later, the step of immersion and oven-dried should repeat until the coating layer meets the requirement, after that it was roasted at $450{ }^{\circ} \mathrm{C}$ for $1 \mathrm{~h}$. The mass percentage of $\mathrm{V}_{2} \mathrm{O}_{5}$ and $\mathrm{WO}_{3}$ are 1.5 and $10 \%$ respectively in this catalyst.

Catalyst test equipment: In order to investigate the performance of the prepared catalyst, NOx reduction characteristics were measured using simulating gas test equipment. Fig. 1 shows the configuration of the simulating setup. The feed gas was consisted by $\mathrm{NO}(0-0.05 \%), \mathrm{NH}_{3}(0.03-0.05$ $\%), \mathrm{SO}_{2}(0-0.01 \%), \mathrm{O}_{2}(5 \%)$, vaporized water $(0-3 \%)$ and $\mathrm{N}_{2}$ (balance). It corresponded to a typical exhaust gas but makeup of by standard gases. The catalyst temperature was controlled with the furnace which controlled by computer and capable of reaching temperatures up to $750{ }^{\circ} \mathrm{C}$. In the simulating gas tests, $\mathrm{NH}_{3}$ was used as the model gas reducing agent. In the actual urea-selective catalytic reduction system, urea and water were injected in the exhaust pipe and decomposes to $\mathrm{NH}_{3}$, which becomes the reducing agent and removes NOx, while in the simulating gas tests this was simplified by directly using $\mathrm{NH}_{3}$. The space velocity was set at $32000 \mathrm{~h}^{-1}$, which was comparative to the mean exhaust flow rates over European steady state cycle test. The gas analysis was performed with a five-way-gas analyzer (AVL DiGas 4000 light).

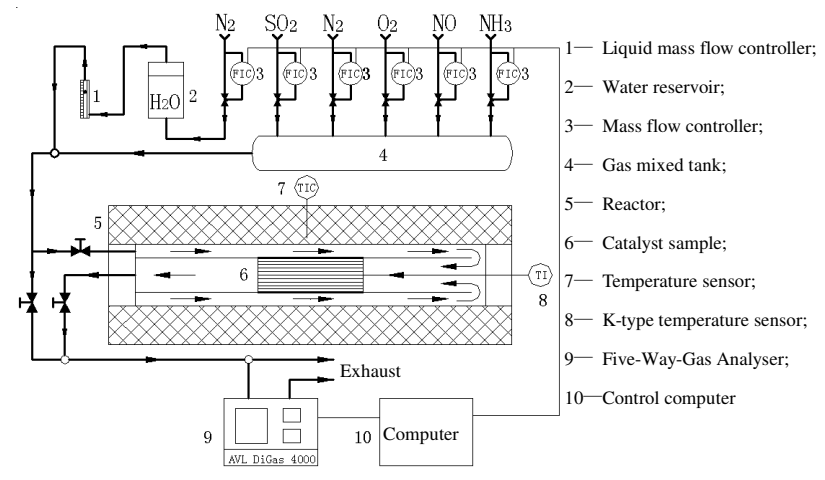

Fig. 1. Setup of simulating gas test

Performance of catalysts: The comparison results of the NOx conversion efficiency at the different temperature between the commercial and prepared catalyst in present study are shown in Fig. 2. The NOx conversion efficiency of two catalysts almost same when the temperature is lower than $240{ }^{\circ} \mathrm{C}$, the conversion efficiency of prepared catalyst in this study raises faster than the commercial catalyst from $240^{\circ} \mathrm{C}$ and $410^{\circ} \mathrm{C}$, it is $12.2 \%$ higher than that of commercial catalyst at $300{ }^{\circ} \mathrm{C}$ and the dominant is always more than $10 \%$ from 300 to 350 ${ }^{\circ} \mathrm{C}$. The light-off temperature of prepared catalyst is $274{ }^{\circ} \mathrm{C}$, it is lower $11^{\circ} \mathrm{C}$ than the commercial catalyst, so the DeNOx performance of prepared catalyst in this study is obvious excelled than that of the commercial catalyst in this range of temperatures. The NOx conversion efficiency of prepared catalyst is lower than that of the commercial catalyst from 410 to $500{ }^{\circ} \mathrm{C}$, the recessive is lower than $10 \%$, but recessive become bigger and bigger when the temperature higher than $500{ }^{\circ} \mathrm{C}$ and the DeNOx performance is inferior than that of commercial catalyst. The top conversion efficiency of prepared catalyst in this study is $93.4 \%$ and that of the commercial catalyst is $94.9 \%$.

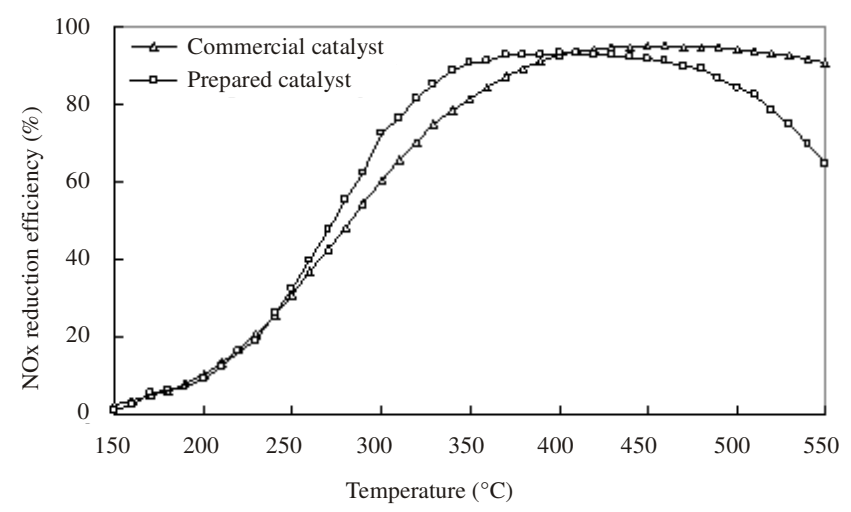

Fig. 2. Comparison of the NOx conversion efficiency between the prepared and commercial catalyst

Dosing system: The function of the urea injection system is injecting proper quantity's urea to exhaust pipe at the adequate time. The quantities of urea were depending upon NOx in exhaust and it is a function of speed, load and temperature of the engine. Furthermore, the effect of selective catalytic reduction catalyst temperature to reaction efficiency should be considered in this system. This system must be detecting the change of the catalyst temperature results from the engine load alteration and have to amend injection strategy for new work condition. The aims are minimization NOx emission and avoidance $\mathrm{NH}_{3}$ slip.

The injection strategy of urea-selective catalytic reduction system is shown in Fig. 3. Based on engine speed and fuel injection dose, the MAP of NOx concentration and needed dose of urea solution on the engine test-bed, after that the temperatures of engine and catalyst was used to amend the MAP. Signals from DCU were sent to the metric and injection unit, so the proper urea dose was injected into the exhaust.

There are many MAPs should be fixed on the engine testbed for calibration of urea injection strategy. These include urea setting injection dose MAP, selective catalytic reduction temperature MAP and corrected selective catalytic reduction temperature MAP. The former two MAPs are steady state; they are achieved from the different steady-state engine work conditions. The calibration of urea setting injection dose MAP was obtained by initial NOx emission and objective per cent conversion. The calibration of selective catalytic reduction temperature MAP was based on temperature distribution and 
their weight factor. The last one is dynamic corrected MAP, it takes effect only when the engine work conditions changing. The change of cooling water is not considered in this process. And the NOx concentration MAP is used for OBD calibration and monitor.

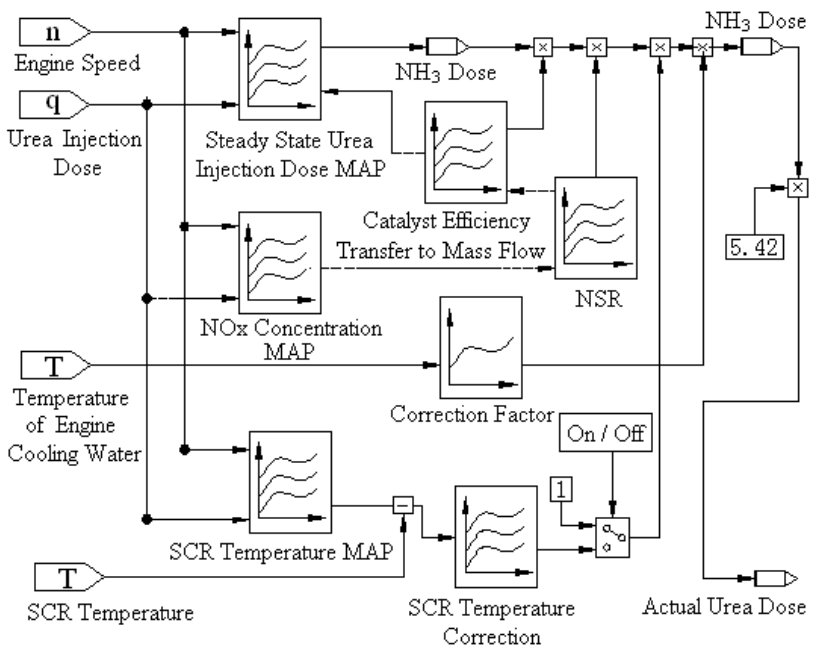

Fig. 3. Urea injection strategy of urea-SCR system

Normally, the temperature sensor was mounted on the pipe before or after selective catalytic reduction to monitor the temperature of catalyst for selective catalytic reduction processing technique. The pipe temperature before selective catalytic reduction will be influenced more by engine work condition than the pipe temperature after selective catalytic reduction, so the temperature sensor after selective catalytic reduction is more suitable to measure selective catalytic reduction temperature than the temperature sensor before selective catalytic reduction. However, we should know the selective catalytic reduction temperature measured by sensor will be retarded, especially when the engine work condition furious changing and the retarded time was decided by heat storage capacity of the catalyst carrier.

In order to correct this retarded time, the steady-state MAP should be dynamic corrected by catalyst temperature and this correct was expressed by corrected parameter. In the MAP, $\mathrm{X}$-axis is the difference between setting temperature and measured value of exhaust and $y$ axis is the setting temperature of exhaust at this engine work condition. These values can be gotten from selective catalytic reduction temperature MAP based on engine speed and injection fuel dose. The calibration of selective catalytic reduction temperature corrected MAP includes two parts: temperature increase and decrease. When the load increasing, measured temperature of selective catalytic reduction temperature was lower than the initialization in MAP before the temperature was steady, so the urea injection dose should be decreased a little than initialization on the MAP, the corrected parameter is lower than 1 . On the other hand, when the load was decreasing, the corrected parameter should be more than 1 , namely the injection dose should be more than initialization on the MAP. This corrected parameter was achieved by experiment. The urea injection dose MAP was shown in Fig. 4. The results indicate that the corrected parameter tends to 1 with the temperature difference decreasing.

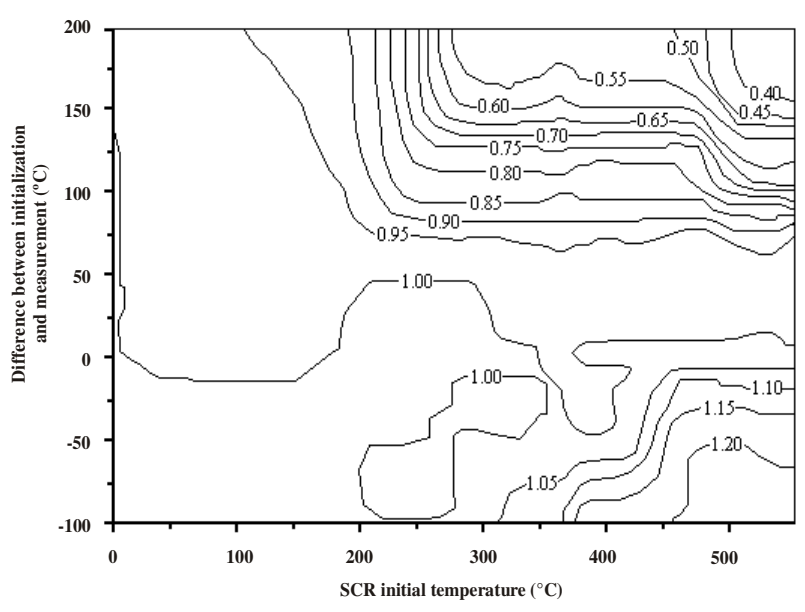

Fig. 4. Corrected parameter of urea injection

The employed diesel engine used in the experiment is a 6 cylinder, 4-stroke, electric controlled common rail fuel system loaded by a dynamometer and supplied with commercially available fuel and lubricating oil, which can meet the Euro III emission level, which detail parameters are shown in Table-1.

TABLE-2

ENGINE PARAMETERS

\begin{tabular}{ll}
\hline Type & Water cooled, four stroke \\
Displacement & $11.6 \mathrm{~L}$ \\
Compression ratio & $17: 1$ \\
Induction type & Turbocharger and inter cooler \\
Fuel system & Electric controlled common rail \\
Standard power & $276 \mathrm{~kW}$ \\
Standard speed & $1900 \mathrm{r} / \mathrm{min}$ \\
Max torque & $1725 \mathrm{Nm}$ \\
Speed for max torque & $1400-1600 \mathrm{r} / \mathrm{min}$ \\
\hline
\end{tabular}

The catalyst experiment apparatus is shown in Fig. 5 and Fig. 6. The NOx reduction catalyst consists of $\mathrm{V}_{2} \mathrm{O}_{5}-\mathrm{WO}_{3} / \mathrm{TiO}_{2}$ prepared in this study, which displays high performance from 250 to $500{ }^{\circ} \mathrm{C}$. The exhaust pressure was measured with a KISTLER pressure sensor. The exhaust temperature was measured before and after selective catalytic reduction with K-type thermocouples. Exhaust was sampled and analyzed before and after selective catalytic reduction. The main experimental installations are shown in Table-3, the other instruments include the air conditioner for intake, fuel consumption equipment, air meter and so on. The test was followed the methods and rules of the European steady state cycle and European transient cycle cycle.

TABLE-3

MAIN EXPERIMENTAL INSTALLATIONS IN THE TEST

\begin{tabular}{lcc}
\hline Name of equipment & Manufacturer & Model number \\
\hline $\begin{array}{l}\text { Dynamometer } \\
\begin{array}{l}\text { Exhaust analysis } \\
\text { system }\end{array}\end{array}$ & $\begin{array}{c}\text { SCHENCK } \\
\text { (HORIBA) }\end{array}$ & HD460 \\
$\begin{array}{l}\text { Constant volume } \\
\text { sampling system }\end{array}$ & HORIBA & $\begin{array}{c}\text { MEXA-7200D } \\
\text { emission analyser }\end{array}$ \\
$\begin{array}{l}\text { Full flow dilution } \\
\text { sampling system }\end{array}$ & HORIBA & CVS-7400T \\
\hline
\end{tabular}



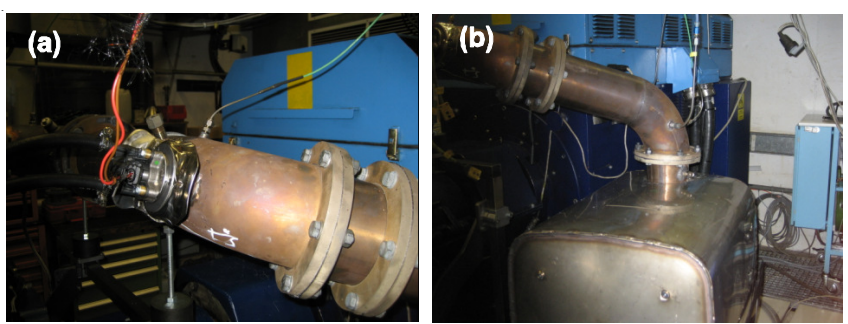

Fig. 5. Urea-SCR system; (a) Urea injection system; (b) SCR catalytic converter

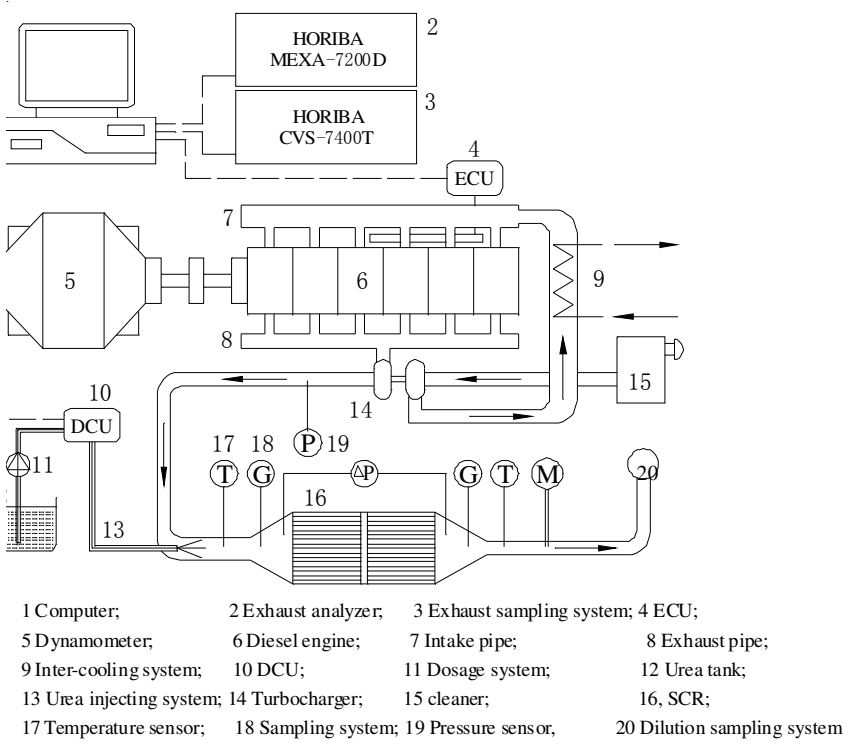

Fig. 6. Setup of simulating gas test

\section{RESULTS AND DISCUSSION}

In order to study the correction to NOx reduction results and $\mathrm{NH}_{3}$ slip, the experiment with catalyst temperature dynamic correction and no correction are compared in test bed. In these tests, idle speed is $600 \mathrm{rpm}$, A speed is 1200 rpm, B speed is $1450 \mathrm{rpm}$ and C speed is $1700 \mathrm{rpm}$.

European steady state cycle results: The results with dynamic correction and no correction are shown in Fig. 7 and Fig. 8. The results indicated that the initial emission is 9.46 $\mathrm{g} / \mathrm{kWh}$ and the emission decrease to $3.22 \mathrm{~g} / \mathrm{kWh}$ and 3.38 $\mathrm{g} / \mathrm{kWh}$ when the selective catalytic reduction worked, the mean quantity of urea slip is $3.88 \times 10^{-6}$ and $3.23 \times 10^{-6}$, mean NOx percent conversion is $66 \%$ and $64.3 \%$ separately. These suggest that the NOx emission with correction was a little higher than without correction, but $\mathrm{NH}_{3}$ slip and urea consumption are lower than that. The corrected value for urea injection quantity is higher than other conditions at A100 work condition, this result in the response of catalyst temperature from idle to A100 is much lower than other conditions and this depends on the volume of catalyst. The volume is bigger, the response time has more delay, at the same time it has relation with the accuracy of steady calibration.

European transient cycle results: Most of the work conditions of the diesel engine are all transient, so in order to improve the response ability, the urea injection quantity calibrated at steady conditions must be corrected. The results in Fig. 9 are corrected and not corrected urea injection quantity at the European transient cycle cycle, the quantity decreases
$15 \%$ after correction, this suggests that urea quantity is tended to decrease at transient correction. And this correction mainly focused on cantonal conditions, these are led by the work conditions in cantonal and heat storage capacity of catalyst.

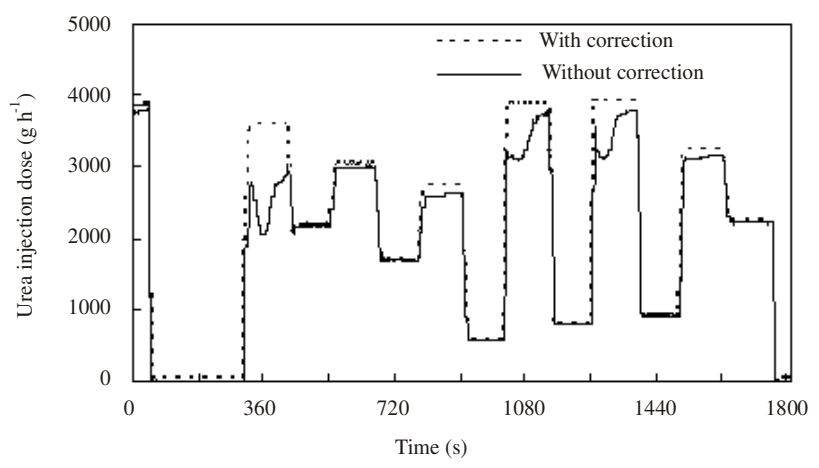

Fig. 7. Compare of urea injection quantity in ESC test cycle

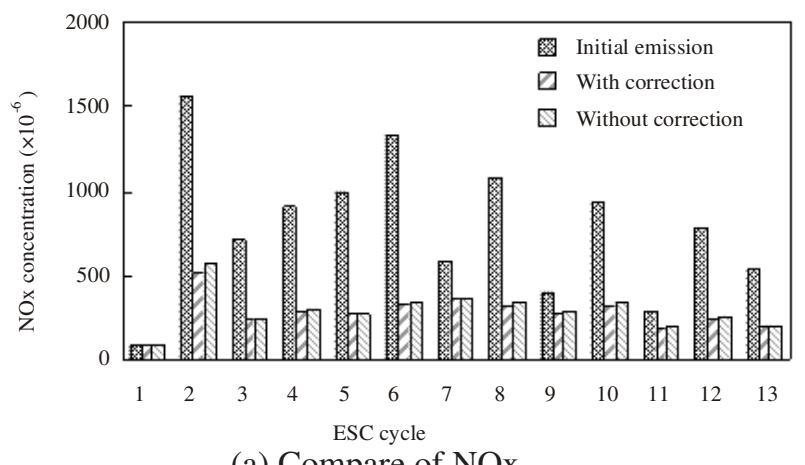

(a) Compare of NOx

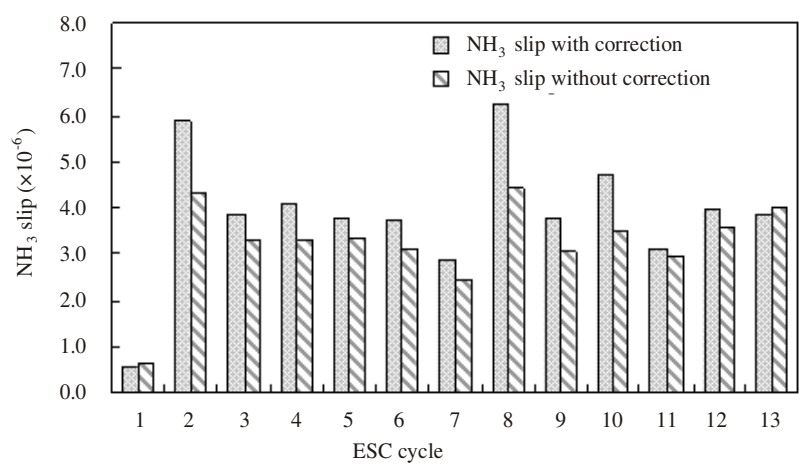

(b) Compare of $\mathrm{NH}_{3}$ slip

Fig. 8. Test results with correction and no correction at ESC test cycle

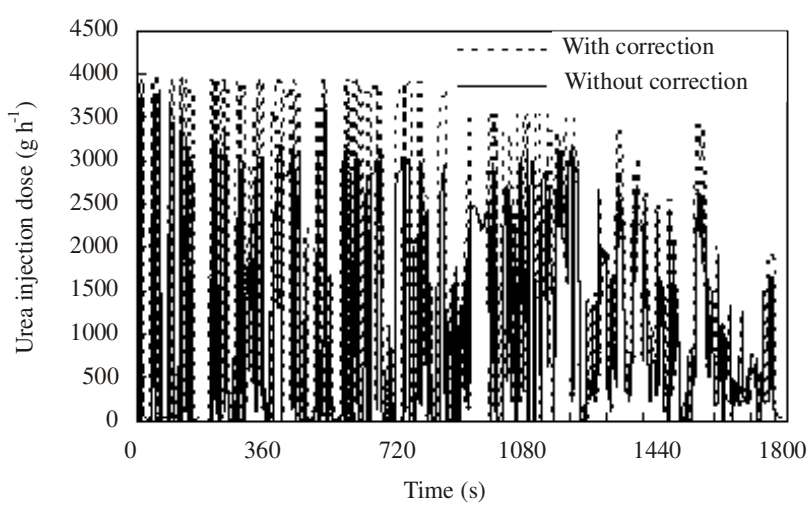

(a) Compare of urea quantity 


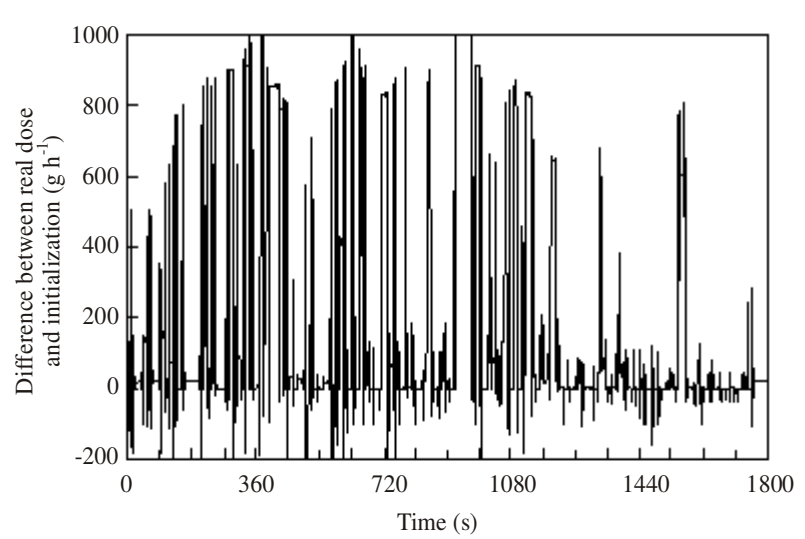

(b) Difference of two conditions

Fig. 9. Results of ETC cycles

The comparison of selective catalytic reduction dynamic correction switched on or off are shown in Fig. 10. The initial emission of this engine is $8.2 \mathrm{~g} / \mathrm{kW} \mathrm{h}$, the value decrease to $3.29 \mathrm{~g} / \mathrm{kW} \mathrm{h}$ and $3.31 \mathrm{~g} / \mathrm{kW}$ h when used selective catalytic reduction system. Mean $\mathrm{NH}_{3}$ slip are $3.04 \times 10^{-6}$ and $1.52 \times$ $10^{-6}$ separately, max transient value are $6 \times 10^{-6}$ and $2 \times 10^{-6}$, mean NOx reductive efficiency are $59.9 \%$ and $59.6 \%$. These results indicate that the $\mathrm{NH}_{3}$ slip and consumption are obviously decrease when the dynamic correction was used and the NOx reductive efficiency almost same with no correct.

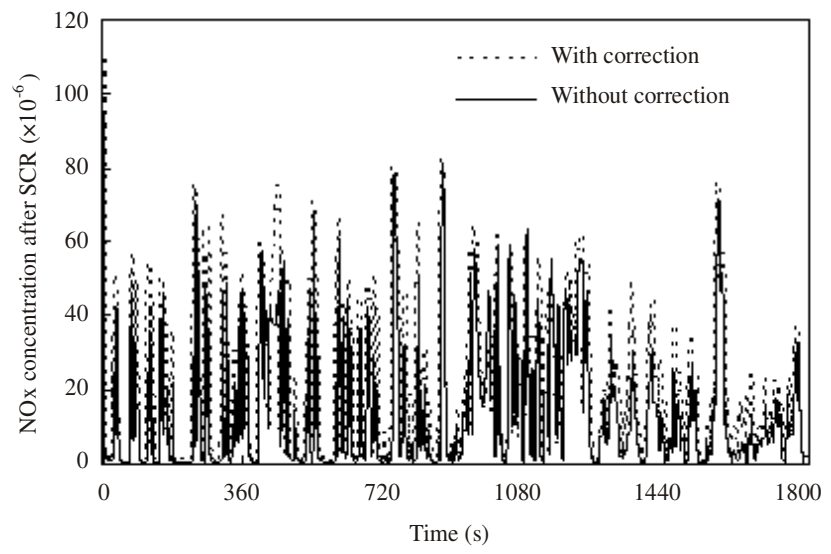

(a) NOx concentration after SCR at ETC cycle

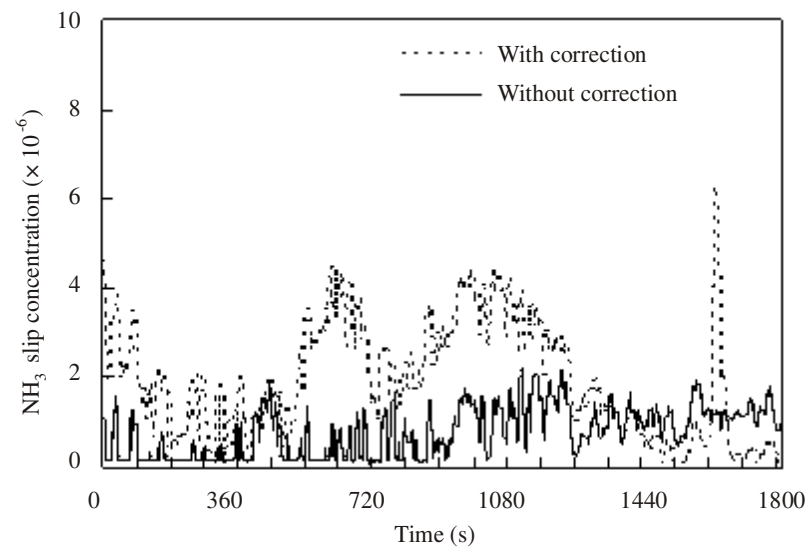

(b) $\mathrm{NH}_{3}$ concentration after SCR at ETC cycle

Fig. 10. $\mathrm{NOx}$ and $\mathrm{NH}_{3}$ results of ETC cycles

\section{Conclusion}

Within this work, we prepared $\mathrm{V}_{2} \mathrm{O}_{5}-\mathrm{WO}_{3} / \mathrm{TiO}_{2}$ catalyst and used it in a $12 \mathrm{~L}$ heavy-duty truck engine and ammonia dosing strategy was used to calibrate transient conditions.

(1) Results of the European steady state cycle and European transient cycle cycle indicate that dynamic correction could meet emission standard and decrease urea consumption obviously and it decreased $\mathrm{NH}_{3}$ slip effectively at transient work conditions.

(2) In order to improve the efficiency of selective catalytic reduction system, the urea quantity should be optimized at steady work conditions.

(3) The volume of selective catalytic reduction should be decreased to reduce its heat storage capacity and improve the transient response to temperature change.

\section{ACKNOWLEDGEMENTS}

This study is supported by Postdoctoral Science Foundation of Shandong Province and Independent Innovation Foundation of Shandong University (IIFSDU).

\section{REFERENCES}

1. M. Koebel, M. Elsener and M. Kleemann, Catal. Today, 59, 335 (2000).

2. D.A. Cooper, Atmosph. Environ., 35, 4189 (2001).

3. S.Z. Bai, J.Z. Tao, Q. Sun, D.H. Tong and G.X. Li, Asian J. Chem., 24, 2135 (2012).

4. E. Hums, S. Liebsch and H. Zellbeck, Ind. Eng. Chem. Res., 43, 8001 (2004).

5. V.I. Parvulescu, P. Grange and B. Delmon, Catalysis Today, 46, 233 (1998); A.P. Walker, R. Allansson, P.G. Blakeman and M. Lavenius, The Development and Performance of the Compact SCR-Trap System: A 4-way Diesel Emission Control System, SAE paper, 2003-01-0778 (2003).

6. B. Scarnegie and W.R. Miller, Recent DPF/SCR Results Targeting US2007 and Euro 4/5 HD Emissions, SAE paper, 2003-01-0774 (2003).

7. R. Nakayama, T. Watanabe and K. Takada, Control Strategy for Urea-SCR System in Single Step Load Transition, SAE Paper, No. 2006-1-3308 (2006).

8. T. Kowatari, Y. Hamada and K. Amou, A Study of a New after Treatment System (1): A New Dosing Device for Enhancing Low Temperature Performance of Urea-SCR, SAE Paper, No. 2006-01-0642 (2006).

9. J. Lei, Ge Yunshan and A.N. Shah, J. Envrion. Sci., 22, 575 (2010).

10. L.J. Alemany, L. Lietti and N. Ferlazzo, J. Catal., 155, 117 (1995).

11. P. Forzatti and L. Lietti, Heterogen. Chem. Rev., 3, 33 (1996). 